Hispania, 2021, vol. LXXXI, n. ${ }^{\text {2 } 269, ~ s e p t i e m b r e-d i c i e m b r e, ~ p a ́ g s . ~ 651-681 ~}$ ISSN: 0018-2141, e-ISSN: 1988-8368, https://doi.org/10.3989/hispania.2021.016

\title{
El caso Climent. ¿Ilustración católica o catolicismo ilustrado?*
}

\author{
Julián Viejo Yharrassarry ${ }^{1}$ \\ Universidad Autónoma de Madrid \\ julian.viejo@uam.es
}

RESUMEN: A partir del análisis de la Carta Pastoral (1769) que el obispo de Barcelona Joseph Climent incorpora a la segunda edición castellana de Las Costumbres de los israelitas (1771), en este artículo se discute acerca de los conceptos: Ilustración católica y catolicismo ilustrado. Con este motivo, se repasan, a su vez, otras cuestiones de primera importancia para situar la existencia, que aqui se afirma, de una Ilustración católica hispana. La aceptación de una versión catolizada de la denominada «sociedad comercial» y de su motor esencial, el amor propio, que habrá de caracterizar dicha Ilustración católica, se irá desenvolviendo a partir del estudio de las diferentes posiciones acerca del lujo que un núcleo de intelectuales destacados del momento recogerá en sus obras.

\section{PALABRAS CLAVE: Ilustración católica; catolicismo ilustrado; sociedad comercial; lujo; amor propio; interés.}

\section{Climent as an example: Catholic Enlightenment or Enlightened Catholicism?}

ABSTRACT: Based on the study of the Pastoral Letter written by Joseph Climent, Bishop of Barcelona, in 1769, which he added to the second edition of Costumbres de los israelitas (1771), this article discusses the concepts of Catholic Enlightenment and Enlightened Catholicism. It also reviews some relevant arguments in favour of the existence of a Hispanic Catholic Enlightenment. Acceptance of the Catholic version of what was known as

* El presente artículo forma parte del proyecto, «Tradición y Constitución. Problemas constituyentes de la España Contemporánea», DER 2014-56291-C3-2-P, financiado por el Ministerio de Economía y Competitividad.

El autor agradece la ayuda de José M. Portillo.

${ }^{1}$ ORCID iD: https://orcid.org/0000-0001-8011-3918

Copyright: (C) 2021 CSIC. Este es un artículo de acceso abierto distribuido bajo los términos de una licencia de uso y distribución Creative Commons Reconocimiento 4.0 Internacional (CC-BY 4.0) 
commercial society, with self-love at its centre, which was to characterize this Catholic Enlightenment, will be analysed through the study of different approaches to the debate on luxury which a set of prominent intellectuals developed in their work.

KeY words: Catholic Enlightenment; Enlightened Catholicism; commercial society; luxury; self-love; interest.

CÓMO CITAR ESTE ARTÍCULO / CITATION: Viejo Yharrassarry, Julián, «El caso Climent. ¿Ilustración católica o catolicismo ilustrado?», Hispania, 81/269 (Madrid, 2021): 651-681. https://doi.org/10.3989/hispania.2021.016.

En una carta pastoral, el por entonces (1766 a 1775) obispo de Barcelona, Joseph Climent, invitaba a sus feligreses a la lectura de la traducción al castellano de la obra del Abate Fleury, Les moeurs des Israélites ${ }^{2}$. Para sorpresa del obispo, dicha traducción, realizada por Martínez Pingarrón en 1737, lejos de ser el éxito editorial que él consideraba debía haber sido, permanecía a estas alturas casi olvidada. Ello le movió a solicitar su reimpresión, que se llevó a cabo, por cuanto, entre otras cosas, sería lastimoso no tener noticia de esta obra de «uno de los hombres más piadosos, y más sabios que ha tenido la Francia». A tal efecto, nuestro obispo colocaba dicha carta, que fue publicada en Barcelona en 1769 , como prefacio a la segunda edición de la obra señalada ${ }^{3}$.

Pero lo que resultaba realmente interesante era la posición que el autor de la pastoral deducía de la lectura de la obra del autor francés. Podría decirse que la carta constaba de dos partes, no formalmente expuestas, en lo que se refería a dicho contenido. Por un lado, transmitía una preocupación por la «reforma» eclesiástica con la declarada intención de acercarla lo más posible a la Iglesia primitiva y la necesidad de que la misma se atuviera, en lo que a la doctrina se refería, especialmente, a los cánones de los Concilios antiguos y a la doctrina de los Padres. Insistía, además, en la necesidad de que la Iglesia cumpliera diversas funciones sociales, muy particularmente la de procurar educación y doctrina católica a los más desfavorecidos mediante el establecimiento de una red educativa en la diócesis ${ }^{4}$. Por otro lado, el resto de la carta era una verdadera diatriba contra el lujo.

De resultas de tales posiciones pueden deducir algunos estudiosos, y muy particularmente Andrea Smidt, quien se ha ocupado incansablemente de nuestro religioso, que Climent podría configurarse como un verdadero ejemplo de

${ }^{2}$ La obra aparecía por vez primera en 1681 y en una segunda edición de 1682 el autor introducía cambios significativos. Fue obra de amplia difusión, tanto en Europa como en América, hasta el mismo siglo XIX.

${ }^{3}$ FLEURY, 1771: II.

${ }^{4}$ CLIMENT, 1788. Una breve e instructiva biografía de Climent en MESTRE: 2009. 
lo que consideran Ilustración católica. La autora señala que en la monarquía hispana la «causa de las Luces» no se percibió como incompatible con lo que considera el elemento crucial de la identidad hispana, el catolicismo. De manera que en estos territorios llegó a desarrollarse una verdadera «Ilustración católica» (Catholic Enlightenment). En este contexto, siempre según Smidt, lo que podríamos definir como «Ilustración española», implicaría una purificación o «enlightening» de la fe católica antes que su abolición. De todos los ilustrados, prosigue la autora, Joseph Climent y Avinent tendría una posición excepcional «for its unique interweaving notions of enlightenment and Catholic reform $\rangle^{5}$.

Nótese que se trata esencialmente de un argumento que se refiere a procesos de reforma internos a la Iglesia, aunque luego pueda argumentarse una extensión al conjunto de la sociedad ${ }^{6}$. Incluso a la hora de calificar lo que denomina «the Age of Reason» señala que de esta puede derivarse tanto un manifiesto ateísmo, como poderosos movimientos de «religious reform whitin the Church ${ }^{7}$. De esta forma, en los territorios católicos europeos no franceses, específicamente en la monarquía hispana y los estados italianos, resultaría posible hablar de una Ilustración católica durante la mayor parte del siglo XVIII. Pero esta forma de Ilustración se equipara con un catolicismo reformado o reforma católica («Reformed Catholicism») como «another form of the Enlightement-reneval within the Church brought about by the return to moral discipline among laity and clergy» ${ }^{8}$. Y ya se van viendo las intenciones de tales planteamientos. En el plan de restaurar la celebración de sínodos diocesanos en Barcelona, suprimidos desde 1755, Climent desarrollaría, de acuerdo con lo sugerido, una manifiesta pretensión de Ilustración católica en la vía de emular la eclesiología de la Iglesia primitiva y el espíritu tridentino9 ${ }^{9}$. Incluso se trataba de una «Ilustración católica» que se contraponía a la de la Monarquía, la cual se orientaba por cauces más impositivos y menos sociales. Sin dejar de reconocer el gran esfuerzo de investigación de la autora, en nuestra opinión tal atribución de Ilustración católica proviene de un malentendido acerca del significado de este sintagma y difícilmente puede aplicarse a nuestro autor. Particularmente su diatriba contra el lujo resultaría un obstáculo a estas alturas del siglo para poder considerar su posición como tal Ilustración católica.

Partiendo de las observaciones de Richard Butterwick y con el fin de evitar anacronismos ideológicamente orientados, en este artículo se propone una interpretación alternativa de esta obra de Climent. En efecto, nos señala el

\footnotetext{
5 SMIDT, 20 (Barcelona, 2002): 91-109; 2010: 403-452.

6 SMIDT, 2006.

7 SMIDT, 2006, «Abstract».

${ }^{8}$ SMIDT, 2006: 18-19. La cursiva es mía.

9 SMIDT, 2006: 7.
} 
autor a partir de una aclaración semántica que un adjetivo es un subgrupo del sustantivo. Así, «catolicismo ilustrado» es una especie del género catolicismo, mientras que la sustancia de «Ilustración católica» implica lo contrario ${ }^{10}$. De esta forma, «catolicismo ilustrado» permanece en esencia catolicismo mientras que «Ilustración católica» es sustancialmente Ilustración. Según nuestro autor, así pues, «[M]uch that has been written about "(the) Catholic Enlightenment' would better classified under "enlightened Catholicism" $>\rangle^{11}$.

Para mejor comprensión, Butterwick nos ofrece algún ejemplo que puede aclarar las cosas. Siguiendo un trabajo del jesuita Mark O'Connor, quien define la «Ilustración católica» como una confrontación con las implicaciones teológicas de la llamada «revolución científica», según nuestro autor aparecería en aquellos momentos la necesidad de aplicarse a discernir entre las ideas aceptables y las dañinas, algo que, efectivamente, estaría motivado por el deseo de un mejor conocimiento de la creación divina. La Iglesia debería al mismo tiempo ser purgada de superstición y de determinados rituales. Según Butterwick, acertadamente a nuestro entender, esto encajaría mejor en el concepto de «catolicismo ilustrado».

Por otra parte, si son los presupuestos ilustrados los que pasan a un primer plano e, incluso, la Iglesia católica es vista principalmente como un medio para su difusión e implementación, si el contexto es el de una cultura y un ámbito político católicos y, además, quien nos manifiesta sus proposiciones forma parte del clero o se trata de un laico católicamente convencido, entonces nos hallaríamos ante lo que podríamos denominar «Ilustración católica»»"

Más allá del debate sobre la pluralidad de ilustraciones, que se asume aquí como presupuesto ${ }^{13}$, en este artículo nos centramos particularmente en la cuestión del lujo en estos momentos y, notablemente, en su vinculación, ampliamente percibida como tal, con la denominada «sociedad comercial» la cual constituye, a nuestro entender, el fundamento compartido por los diversos planteamientos que pueden ser calificados de «ilustrados». Cabe destacar que nuestra intención no es un repaso global sobre las discusiones acerca del lujo en los momentos en que escribía Climent. El objeto del artículo es la distinción entre «Ilustración católica» y «catolicismo ilustrado» y en este sentido tanto la cuestión del lujo como el propio Climent resultan funcionales al objetivo perseguido. No se trata pues, tampoco, de un trabajo sobre el mismo obispo ni mucho

${ }^{10}$ BUTTERWICK, 2008: 204.

${ }^{11}$ BUTTERWICK, 2008: 204. El sintgama «catholic Enlightenment» fue rechazado, en su momento, por Plongeron y Rogier por excesivamente reductivo, en su opinión, del fenómeno.

12 BUTTERWICK, 2008: 204-205.

13 VIEJO, 2018: 15-41. VIEJO y PORTILLO, 26 (Madrid, 2013): 127-143. 
menos se pretenden abarcar todas las cuestiones del XVIII hispano, ni todos los planteamientos historiográficos realizados a lo largo del tiempo sobre ellas.

Conviene, por otra parte, indicar brevemente que nuestra concepción de Ilustración, o ilustraciones, coincide de manera general con la señalada por John Robertson (quien, por otra parte, no suscribe la idea de una pluralidad de ilustraciones) para quien se trataría de un movimiento de carácter esencialmente intelectual, vinculado primordialmente a las ideas y al pensamiento y que adquirió entidad propia entre los años 40 y los 90 del siglo XVIII ${ }^{14}$. Por supuesto, habida cuenta de tal dimensión intelectual, en el presente trabajo se lleva a cabo una opción historiográfica consciente. La vertiente historiográfica que, primordialmente, se atiende es la de la «historia contextual» vinculada a la denominada Escuela de Cambridge, muy particularmente a la hora de llevar a cabo las reconstrucciones historiográficas que resultan oportunas para nuestro cometido.

\section{LUJO Y SOCIEDAD COMERCIAL}

En una reseña al Antimachiavelo que aparecía publicada, sin firma, en la Nouvelle Bibliotèque ou Histoire Litéraire des nouveaux écrits qui se publient, en noviembre de 1740, Voltaire comparaba la obra compuesta junto a Federico II de Prusia contra Maquiavelo con el Telémaco de Fénelon (una obra de gran éxito e influencia durante todo el siglo XVIII y por toda Europa ${ }^{15}$. Nos indicaba el autor que a efectos de emanar la felicidad del mundo de un libro el Antimaquiavelo superaba con creces a la obra del arzobispo. Entre otras consideraciones señalaba:

Le roman [el Télemaco de Fenelón] inspire une vertu presque idéale, des principes de gouvernement faits pour les temps fabuleux qu'on nomme héroïques [...] il bannit entièrement le luxe, qui est pourtant l'âme d'un grand État et le principe du commerce ; l'Anti-Machiavel inspire une vertu d'usage : ses principes sont aplicables à tous les gouvernements de l'Europe ${ }^{16}$.

A estas alturas, la cuestión del lujo había devenido en una cuestión esencial para el discurso intelectual europeo. Saint-Lambert, en su artículo a propósito de aquel que aparecía en la Encyclopédie, como nos recuerda Istvan Hont, señalaba que el lujo no era meramente un fenómeno económico, sino, además, la cuestión central de la modernidad tanto en el plano moral, como

${ }^{14}$ ROBERTSON, 2005.

${ }_{15}$ De especial interés para la Monarquía Hispánica, IÑURRITEGUI, 8/1 (2019): 1-14.

16 VOLTAIRE, 1879, tomo 23: 159-163. 
en el político ${ }^{17}$. Por su parte, Maxine Berg y Elisabeth Eger, recientemente nos recuerdan:

Luxury was a key issue at the hearth of intellectual discourse in political economy, moral philosophy, literary culture and aestetics trough the eighteenth century ${ }^{18}$.

Ciertamente, el debate recurre a tradiciones discursivas que podrían remontarse incluso a la Antigüedad, pero en el siglo XVIII las discusiones sobre el lujo se extienden más allá de su atención hacia la corrupción de las élites. Se producirá una creciente distinción entre el «nuevo» y el «viejo» lujo, entre lujo «moderno» y lujo «antiguo». Por lo que nos interesa, dicho debate se convierte en inseparable del debate sobre el comercio y sobre «la sociedad comercial», lo que acaba por conducir a la cuestión acerca del lujo en una cuestión «not just about goods but about social behaviour» $\rangle^{19}$. Christopher Berry, en un memorable trabajo, ya nos advertía de ello hace tiempo. En lo que él llamaba un proceso de «demoralisation» del lujo, establecía una comparación con lo que denomina el paradigma aristotélico dominante ${ }^{20}$. Partiendo de los conceptos de «deseo»y «deficiencia», señala Berry, Aristóteles también nos presentaba la existencia de un nexo entre ambos. Para Aristóteles, sin embargo, la deficiencia siempre se analiza en términos de un estándar normativo, un objetivo propio (telos). En el caso de los seres humanos, todos desean el estadio que él llama eudaimonia, un fin perfecto y autosuficiente. Aquellos que alcanzan dicha eudaimonia, están llevando a cabo una vida como debe ser y, dado que se trata de una vida sin falta o deficiencia alguna, el deseo para estos seres humanos ha dejado de existir. En este sentido, el «deseo» es limitado, lo es por su fin. De ahí que la persecución de deseos más allá de su apropiado fin resultaría en una incapacidad para vivir como un ser humano debe. Es decir, se trataría de una falta de virtud.

La visión «moderna», por el contrario, rechaza esta perspectiva teleológica $\mathrm{y}$, por ello, no admite la posibilidad de la existencia de un estadio perfecto y privado de deseo. Y, por lo tanto, rechaza, además, la idea de que los deseos puedan ser limitados por algún tipo de fin fijado. Ahora bien, una vez que la estructura objetiva y teleológica pasa a ser devaluada, pudiera pensarse que la

17 HONT, 2006: 379.

18 BERG y EGER, 2003a: 5.

19 BERG y EGER, 2003b: 7-22. Refiriéndose a Mandeville hacen también explícita esta relación las autoras: «His challenge [de Mandeville] set the framewwork for subsequent debate and, more significantly, the association of luxury and trade opened a much broader discussion of comercial expansión and consumer society», BERG y EGER, 2003b: 10. Para Istvan Hont es Fénelon y el Salentum de sus Aventures de Télémaque quien configura el armazón del debate y a quien precisamente Mandeville se encarga de refutar. HONT, 2006: 380.

${ }^{20}$ BERRY, 1994: 113-114. 
consecuencia resultante sería un ineludible desorden. Sin embargo, no es así por cuanto la «psicología moderna» identifica un criterio de certeza y de previsibilidad en los asuntos humanos de resultas de la naturaleza propia del ser humano: «All humans enjoy pleasure and avoid pain» ${ }^{21}$.

La evidencia más palpable de dicha constante es la preeminencia del «interés» en la naturaleza humana, Así, Berry establece igualmente la concomitancia de lujo y sociedad comercial, cuyo fundamento es el «self-interest». Y por ello mismo, el orden político debería basarse en facilitar, no erradicar, la satisfacción de los deseos ${ }^{22}$.

Por ello, continuamos con Berry, el debate sobre el lujo en el siglo XVIII sería al mismo tiempo un debate sobre el carácter de la sociedad contemporánea y, a la vez, una característica de dicha sociedad, una sociedad que es descrita como comercial ${ }^{23}$.

En una obra reciente y en un capítulo dedicado a la felicidad, David Wootom nos ha señalado que, en gran medida, el turning point sobre la felicidad y sobre la propia sociedad comercial ya se habría iniciado con Hobbes ${ }^{24}$. Lo novedoso en el propio Hobbes consistiría en establecer un relato de las relaciones sociales en las que el concepto de competición resulta nuclear. Recuérdese que Aristóteles había señalado que, a menos que ocurriese algo terrible, cualquiera puede alcanzar eudaemonia si se convierte en un tipo determinado de persona. Por su parte, Epicuro indicaba que una vez alcanzada ataraxia uno puede permanecer permanentemente en este estado. Hobbes, sin embargo, señaló que los seres humanos se hallaban continuamente «in pursuit of their Passions», esto es, nunca llegarían a alcanzar su objetivo, o a conseguir aquello que se habrían propuesto, precisamente de resultas de esa insaciable persecución de sus pasiones que solo acabaría con la muerte. En estas circunstancias, no es de extrañar que Hobbes niegue la existencia de summum bonum alguno ${ }^{25}$.

Por su parte, Anoush Terjanian afirma también, con las matizaciones que posteriormente señalaremos, la correspondencia entre lujo y sociedad comercial en la Francia del siglo XVIII. Particularmente, la conocida como querelle du luxe, iniciada en los años treinta de dicho siglo, resultaría de una creciente conciencia de la ubicuidad y permanencia del comercio. «Indeed, señala, the way people spoke and wrote about luxury tended the way they understood commerce ${ }^{26}$. Incluso, aunque otros autores de referencia, como John Sho-

${ }^{21}$ BERRY, 1994: 113.

22 BERRY, 1994: 115.

23 BERRY, 1994: 15.

${ }^{24}$ WOOTOM, 2018.

25 WOOTOM, 2018: 77.

26 TERJANIAN, 2013: 16. Algo similar señala Berry, en este caso refiriéndose a las leyes suntuarias: "Generally speaking... the attitude towards the efficacy and proprierty of sumptuary laws is one resonable reliable indicator of a writer's conception of luxury 
vlin ${ }^{27}$, introduzcan la matización, igualmente para el caso francés, de que, tras la Guerra de Los Siete Años (1759-1763), acabó por producirse una «crítica política» del lujo que, finalmente, delimitó comercio y lujo, Terjanian insiste en que se pueden detectar determinadas instancias en el lenguaje del lujo en las que la crítica política se ve complementada por una poderosa afirmación de $\mathrm{este}^{28}$. El mismo Sholvin inscribe sus consideraciones, en un artículo reciente, en una línea no muy diferente ${ }^{29}$. El debate acerca del lujo reflejaba «the political, cultural, and moral status of comercial modernity» ${ }^{30}$. Y, a pesar de una reorientación más critica a partir de 1760 respecto de la apología de la primera mitad de siglo, el esfuerzo ilustrado de dichos apologetas del lujo por señalar los beneficios de la sociedad comercial fue todo un éxito. ${ }^{31}$

Retengamos dicha asimilación a los efectos, precisamente, de analizar la posición de alguien que rechaza el lujo, el obispo Climent. Veremos más adelante de qué manera, pero ahora hemos de aclarar, en primer lugar, a qué nos referimos cuando hablamos de «sociedad comercial». Reconstruimos brevemente a continuación algunas de las más destacadas posiciones historiográficas al respecto (siempre en el marco de la historia de los contextos discursivos) y concluimos con una definición, la de Adam Smith, que creemos puede aplicarse de forma general a la consideración de dicho fenómeno.

\section{Historiografía, COMERCIO, AMBIVALENCIAS COMERCIALES}

«Sociedad comercial» es un sintagma de amplio uso hoy en día entre los estudiosos del siglo XVIII. Conviene, sin embargo, alguna aclaración al respecto. Como señala J. Pocock ${ }^{32}$, el comercio forma parte esencial de la autopercepción de la propia Ilustración en toda Europa. Según este autor, una parte sustancial de lo que nosotros definimos como Ilustración es en gran medida el resultado de la salida de la época de las Guerras de Religión en las que se habrían visto envueltas Francia y los Países Bajos desde 1560 hasta 1598, el Sacro Imperio, desde 1618 hasta 1648, y los Tres Reinos británicos, desde 1637 hasta 1652 y nuevamente desde 1688-91. La emergencia del periodo de las

(and also of what comes to be seen as its concomitant, namely comercial society», BERRY, 1994: 113.

27 SHOVLIN, 2006.

28 TERJANIAN, 2013: 46.

29 SHOVLIN, 2008: 203-222.

30 SHOVLIN, 2008: 205.

31 SHOVLIN, 2008: 217. Saint-Lambert vendría a manifestar tal posición más moderada a la hora de representar los beneficios del lujo en el contexto institucional francés, sin negarlos.

32 POCOCK, 17/1 (Londres, 2007): 55-63. 
Guerras de Religión supondría la emergencia, también, de una fase de guerra mercenaria en Europa y su sustitución por un ejército permanente, una fuerza profesional al servicio de un poder político capaz de desarrollar sistemas de crédito público que convirtieron en continua su disposición para retribuir dicho ejército $^{33}$. Hacia 1700 , ya era percibido como un fenómeno nuevo y, dado que se sustentaba fundamentalmente en la capacidad de mantener un sistema sólido de crédito público, aquel territorio que tuviese la capacidad de generar una mayor confianza en su propia economía tendría más posibilidades de hacerse con la victoria en los enfrentamientos armados. El crédito del país se vinculaba al comercio del mismo y apareció así la imagen de una sociedad civil que era, al mismo tiempo, una «sociedad comercial», basada en un intercambio constante entre sus miembros no solo de bienes materiales, sino también de ideas, lenguaje, valores y cultura. La idea no era nueva pero su realización se percibía que había sufrido un incremento evidente en la Europa del momento. De la misma manera, lo que este autor llama la «confederación de Estados» que habría surgido tras la Paz de Utrecht (1713) se mantendría así unida mediante dos fuerzas: el comercio y los hábitos sociales (manners, moeurs), entendiendo por los últimos el complejo de usos cívicos y culturales que una sociedad en su plenitud desarrollaba. Era este código de usos lo que se quería que diferenciara la Europa de la Ilustración de la virtud cívica de la historia antigua o de la virtud cristiana del pasado inmediato ${ }^{34}$.

Por su parte, las modificaciones en la forma de comprender el derecho natural, particularmente desarrolladas en ámbito protestante, remaban en la misma dirección. La concepción de una «sociabilidad natural» o el mantenimiento de un «instinto» por la sociabilidad propio del ser humano que se mantuvo dominante hasta (incluido) Grocio, resultaba difícilmente compatible con las actividades esencialmente competitivas de una «sociedad comercial». Sin embargo, ya Hobbes había negado la sociabilidad natural del hombre y, posteriormente, Pufendorf, al no aceptar la naturaleza contractual de la sociedad y afirmar su surgimiento a través del tiempo como el resultado de convenciones artificiales establecidas para controlar sus pretensiones insociables, incorporó al derecho natural de nuevo cuño este planteamiento ${ }^{35}$.

Según John Robertson, el reconocimiento de la centralidad de las relaciones económicas, con su dimensión inseparablemente moral, resultaba crucial para la vida social, pero no era suficiente. Era, además, necesario que la nueva ciencia de la Economía Política se configurase y presentase como un conjunto de principios coherentes ${ }^{36}$. Así, «the rise of political economy to intellectual pro-

33 POCOCK, 17/1 (Londres, 2007): 62-63.

${ }^{34}$ POCOCK, 1975; 1999-2015.

${ }^{35}$ ROBERTSON, 2013: 24.

${ }^{36}$ ROBERTSON, 2013: 24; 2001. 
minence» debe comprenderse en un contexto más amplio que el de un crecimiento de la producción de obras puramente económicas respecto del siglo y medio anterior. Un contexto, señala Robertson, que se hallaría en la transformación de varias de las formas tradicionales de análisis del comportamiento moral y político y, particularmente, en el surgimiento de una nueva manera de abordar la sociabilidad, o el desarrollo de la sociedad, en el que las cuestiones económicas adquieren una importancia mucho mayor.

No debe pasarse por alto que un número apreciable de historiadores, formados en la línea historiográfica de Istvan Hont, viene realizando una crítica a lo que denominan la «teoría del doux commerce», cuya expansión atribuyen especialmente a Albert Hirschman, inventor del sintagma, y que han convertido en su gran difusor a John Pocock. Según tales planteamientos la «teoría del doux commerce» y el canon de autores que se estudian a la hora de referirse al fenómeno histórico del comercio resultarían de una atribución de finales del siglo XIX que buscaba legitimar el mismo como medio para superar la guerra entre naciones y conseguir un mundo de relaciones internacionales fundado en la «paz del comercio» ${ }^{37}$.

A este respecto, ya nos había advertido el propio Hont de la existencia de lo que Hume denominaba Jealousie of Trade. Para Hont, la expresión se refiere a una conjunción particular entre política y economía que surge cuando el éxito en el comercio internacional se convierte en una cuestión de supervivencia militar y económica. Es en el ámbito de estas relaciones internacionales y, muy particularmente, en las disputas coloniales donde tal fenómeno es especialmente perceptible. Es el derecho a los nuevos territorios, a los nuevos recursos productivos a través de la conquista o de la primera ocupación, que despertó el interés de un gran número de juristas ${ }^{38}$. Serán sus teorías acerca de la propiedad privada las que proveerán de argumentos y de legitimaciones a las políticas fundadas en una expansión territorial global. De esta forma, «Jealousy of Trade signaled that the economy had become political. It inaugurated global market competition as a primary state activity $\rangle^{39}$.

Sophus Reinert, en la misma senda que Hont, señala que su Translating Empire trataría de mostrar los conflictivos fundamentos de la economía política en el siglo XVIII y el papel fundacional que en la institucionalización de la misma habrían jugado las traducciones de diferentes obras y sus prácticas, las presiones de la competencia internacional y algo que los contemporáneos conocían como «emulación» que, siempre según Reinert, era una alternativa noble

37 HIRSCHMAN, 2013.

${ }^{38}$ HONT, 2005: 13.

${ }^{39}$ HONT, 2005: 4, 7. 
a la envidia y vendría a significar el deseo de imitar, incluso mejorar, a quienes se tiene por superiores sin dañarlos en el proceso ${ }^{40}$.

A partir de un detenido análisis de las vicisitudes del Essay on the State of England, de John Cary, de su traducción y adaptación a contextos culturales diferentes (Francia, Italia, Alemania y Escandinavia), el autor nos va mostrando de qué manera la Economía Política devino gradualmente el marco de referencia (analítico y de acción política) para aquellos territorios que luchaban por su supervivencia en un cada vez más conflictivo contexto geopolítico euro$\mathrm{peo}^{41}$. En esta línea, el propio autor se reconoce deudor de la obra casi simultánea de Paul Cheney, Revolutionary Commerce ${ }^{42}$. Cheney nos indica los perversos efectos de la proyección de los fundamentos de la economía ya constituida en disciplina durante el siglo XIX hacia el pasado y la tendencia a buscar, a partir de este punto de partida de investigación, los principios sobre los que se fue constituyendo como tal disciplina. De ello resultaría una suerte de narrativa de corte whig que intentaría poner de manifiesto un desarrollo inevitable del «laissez-faire ${ }^{43}$. Algo que, además, habría llevado a la elaboración de una suerte de canon de pensadores de la economía política que de una forma más evidente -desde el punto de vista de tales retroproyecciones- pudieran aparecer como precursores de la disciplina económica de los siglos XIX y XX, al tiempo que se interpretaban sus obras en tales términos. Así, señala Cheney, si entendemos la historia de dicho proceso como una progresión teleológicamente guiada a partir del mercantilismo, el material de estudio alcanzaría una suerte de ordenación propia: «Just situate an autor within this teleological arc and affix the label "pre-", "post-", "neo-" or "anti-" "as appropiate"»" ${ }^{44}$. Pero Cheney y Reinert van bastante más allá. Su propuesta acabará en una dura crítica a la denominada teoría del «doux commerce», a aquello que consideran una suerte de «irenic conception of eighteenth-century comercial capitalism» ${ }^{45}$.

De la misma forma que en el caso de Cheney, y volviendo a la obra de Reinert, es esta una clamorosa llamada de atención historiográfica. Particularmente, dicha obra arremete contra la línea de flotación de la señalada «teoría del doux commerce». Insiste el autor en la existencia de un sector mayoritario de pensadores que consideraron que la clave del mundo en el que vivían, que no deja de ser el mundo del comercio, es la competición internacional. De esta forma, lejos de concretarse una separación entre comercio y militarismo o guerra, esta conjunción no hizo sino acrecentarse, especialmente tras la Guerra de

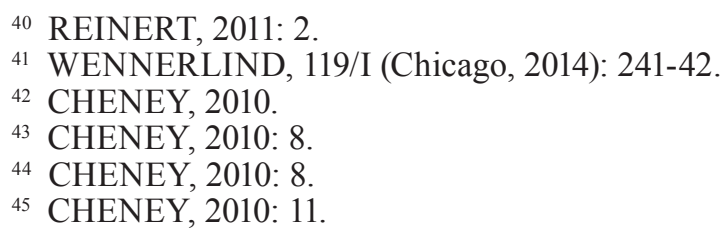

${ }^{40}$ REINERT, 2011: 2.

41 WENNERLIND, 119/I (Chicago, 2014): 241-42.

${ }^{42}$ CHENEY, 2010.

${ }^{43}$ CHENEY, 2010: 8.

${ }^{44}$ CHENEY, 2010: 8.

${ }^{45}$ CHENEY, 2010: 11. 
los Siete Años, una ruptura que es compartida por la totalidad de los críticos con esta teoría de «doux commerce». El punto de partida gira en torno a la idea de que el sistema de equilibrio político en el siglo XVIII es un sistema fundado en el equilibrio económico, en la riqueza y que, por esta vía, Inglaterra, por ejemplo, puede «imponer su ley» [una variación internacional del clásico condere leges] al resto de los países. De forma que el comercio, el sistema del comercio, la «sociedad comercial» no es necesariamente un sistema de paz, una garantía de libertades para todos. Lo que verdaderamente se produce es una conjunción que se admite inseparable entre comercio y conquista, una conquista que puede ser militar o económica ${ }^{46}$.

Por lo demás, la Economía Política no sería tan solo la ciencia de reformar instituciones y hacer ricos a los reinos, sino que tendría como fin convertir a las naciones en entidades viables en el seno de las rivalidades internacionales y con esa finalidad su principal misión consistía, a la postre, en informar al público de la congruencia entre conquista y comercio ${ }^{47}$.

Matiza, en cualquier caso, que no se trata de negar la existencia de muchos autores que proponen la sustitución de la guerra por el comercio como garantía de paz, sino de afirmar una postura antagónica que ve el equilibrio en la potencia derivada de la riqueza de un país. De forma que, siempre según el autor, si el equilibrio de poder y la balanza comercial eran lo mismo, las relaciones internacionales no conocían la paz (nótese una vez más el planteamiento internacional): «Far from pacifying it, commerce had rendered conflict endemic in the modern world $\rangle^{48}$

Como ya señalamos, el creador de la «teoría del doux commerce» es Albert Hirschman. Aprovechando diversos términos de proximidad semántica utilizados por Montesquieu en su Esprit des Loix, aquel acabará por configuar el sintagma «doux commerce» con el significado de una sustitución general de los enfrentamientos armados a la antigua usanza por el comercio, que vendría a instaurar una época centrada en la paz. El primer problema de índole intelectual con el que nos hemos de enfrentar en el caso de esta deslumbrante (en su momento) teoría es que su punto de partida se centra en la búsqueda de los fundamentos intelectuales que favorecieron la irrupción del capitalismo ${ }^{49}$. En nuestra opinión este del anacronismo es el problema mayor tanto del trabajo de Hirschman como de aquellos otros autores que siguen lo que Reinert llama «el

46 «Commerce, like war, could be a means of coercion and a path to empire», REINERT, 2011: 7. ROUSSELIÈRE, 74/3 (Cambridge, 2012): 530-33.

${ }^{47}$ REINERT, 2011: 25; 115/5 (Chicago, 2010): 1395-1425.

48 REINERT, 2011: 16. Cheney, por su parte, nos indica que «it is essential to recognize that comercial warfare only become intolerably reprensive and politically explosive once it expanded to Europe's colonial periphery- and in particular the Atlantic world», CHENEY, 2010: 12.

${ }^{49}$ HIRSCHMAN, 2013. 
canon». En nuestra opinión, Xavier Lafrance tiene razón al afirmar tales disfunciones históricas en libro dedicado a la formación de la clase obrera y la irrupción del capitalismo en Francia ${ }^{50}$. Siguiendo líneas ya marcadas por otros autores, particularmente Robert Brenner, Lafrance afirma la necesidad, precisamente, de comenzar con un intento de acercamiento a la cuestión propuesta de una forma históricamente fundada. Se trata de una obra que el mismo autor no duda en calificar de provocativa y algo irónica en la medida en que, después de todo, existe una extensa literatura acerca de la historia del capitalismo francés. Sin embargo, aunque muchas de esas obras pueden constituir un apoyo fundamental para el desarrollo del argumento que nuestro autor nos presenta, «I contend that most of these contributions take for granted the existence of capitalism without really considering its historical origins». Las explicaciones, siempre según Lafrance, resultan circulares, y el capitalismo es tratado como si surgiera de unas «preexiting, embryonic capitalist dynamics that were already gestating in the womb of feudalism or absolutism». Y lo que resulta del mayor interés para nosotros, el capitalismo es, así, presentado como una extensión puramente cuantitativa del comercio, «in ways that resonate with the comercial model tied to the historical narrative put forwards by Enlightenment thinkers and classical political economists $\rangle^{51}$.

Con todo, no debe olvidarse que el mismo Hirschman no deja de señalarnos las posibilidades de corrupción, particularmente moral, que el propio Montesquieu advierte acerca del comercio. Montesquieu mismo, por otro lado, justifica la conquista de Irlanda por parte de Inglaterra por cuanto esta benefició al comercio inglés.

También John Pocock nos hace desde hace tiempo tales advertencias y, aunque tiende a ser «la bête noire» -siempre en términos intelectuales- de quienes critican la teoría del «doux commerce», las cosas no son tan evidentes, incluso, al contrario. Ya desde su Machiavellian Moment $(1975)^{52}$, dedicaba una extensa sección a calibrar las diferentes posiciones y las contradicciones morales que generaba el comercio en tanto que etapa nueva en la historia. Algo que no dejará de prodigar en artículos y libros posteriores. En un trabajo publicado en su Virtue, Commerce and History, señalaba la autopercepción que los mismos «apologistas» del comercio detectaban en el desarrollo de este:

They added that the growth and diversification of human potentialities throught the developemenet in history of capacity to produce and distribute was the true story of the human personality in society and that any loss of virtue which special-

${ }^{50}$ LAFRANCE, 2019.

${ }^{51}$ LAFRANCE, 2019: 1.

${ }^{52}$ POCOCK, 1975: 462-505. 
isation entailed was a price well paid for the increase in economic, cultural and psychich capacity ${ }^{53}$.

En un artículo, en este caso reciente, Pocock nos ofrece de forma implícita una sucinta aclaración de toda la trayectoria de su planteamiento. Retomando algunas de las primeras consideraciones que hacíamos al comenzar con la aproximación al entendimiento de la «sociedad comercial», nos señala el autor que tras la emergencia de las Guerras de Religión y la irrupción del temor al desarrollo de una monarquía universal, que pudiera desarrollar en primer lugar la Casa de Austria, particularmente su rama hispana y, posteriormente, la Casa de Borbón, la solución que los contemporáneos encontraron para tales temores fue la de percibir Europa como una pluralidad de estados (especialmente monarquías) capaces de controlar el disentimiento religioso, de pagar ejércitos permanentes que actuarían como sus instrumentos «and conduct relations with it neighbor states that included war but could be concluded by treaties $\rangle^{54}$. Los historiadores que escribían tras la paz de Utrecht concibieron que esta habría establecido el sistema europeo de estados sobre unas bases firmes, y su énfasis en las condiciones culturales y sociales que tales estados compartían les permitirían no hacer desaparecer las guerras, sino concebir que, incluso, estas podían conducirse en tanto que miembros de una comunidad civilizada. «This was the "Enlightened utopia" of 1713-1789» $\rangle^{55}$.

Sin embargo, a nuestro autor no se le escapa que el lapso entre Utrecht y la Revolución no fue precisamente un momento en el que los estados ilustrados condujeran sus guerras bajo el control del ius belli ac pacis y de la razón de Estado. Como Pocock señala, el comercio en el que dicha utopía se fundaba era global, no solo intraeuropeo, y esta fue la era de la denominada «segunda Guerra de los Cien Años» entre Inglaterra y Francia, que se desarrolló en los territorios coloniales y transoceánicos. La posibilidad que ello supuso de generar odios «nacionales» se vio, además, favorecida por el hecho de que las guerras se jugaban más allá de Europa, lejos del ámbito en el que se afirmaba que la existencia de una cultura y una historia comunes potenciaban los efectos civilizadores del «doux commerce». Ahora bien, tales desenvolvimientos oceánicos podían desarrollar un efecto rebote sobre la propia Europa, sobre la percepción de unos estados europeos respecto de otros. Franceses e ingleses podían acusarse mutuamente de desarrollar una guerra propia de «salvajes» y con ello de importar este proceder a la propia Europa, «if there was no peace

${ }^{53}$ POCOCK, 1985: 462-505.

54 POCOCK, 2018: 268. La cursiva es mía. Para los tratados en estos momentos, ALIMENTO y STAPELBROEK, 2017: 1-75.

55 POCOCK, 2018: 269. 
beyond the Line, the Line itself failed to protect the zone of civilty ${ }^{56}$. Y, como ya señalamos, la cuestión se volvió especialmente peliaguda durante el periodo de la Guerra de los Siete Años, en este caso para Francia, y el periodo que termina en 1783, para Gran Bretaña.

No deja Pocock de referirse a la más destacada respuesta literaria a los problemas derivados de lo que él denomina «the crisis of seaborne empires», que, a su vez, es punto de referencia fundamental de los críticos de la denominada teoría del «doux commerce»: la Histoire Philosophique et politique du commerce et des établissementes des Européens dans les deux Indes, promovida y editada por el abate Raynal y fruto de la colaboración entre varios autores ${ }^{57}$. La obra, según Pocock, debe entenderse, además de como un supuesto clásico del anticolonialismo, como una historia filosófica del comercio. Y, en este sentido, presenta una manifiesta «ambivalencia», destacando el comercio como fuente de «civilidad» pero sin dejar de reconstruir toda una serie de males que el comercio mismo habría ocasionado desde que la navegación abrió Asia, Africa y América a la posibilidad de ser explotadas por los europeos. Los contemporáneos eran conscientes de los males que podría acarrear el comercio. Pocock no deja de recordárnoslo.

Otro aspecto que se propone por los críticos de la teoría del «doux commerce», ya desde Istvan Hont en su Jealosusy, es la dificultatd de dar por muerta la teoría republicana de la corrupción. Pues bien, Pocock, que ya habría señalado que el mundo de los hábitos y costumbres se configuró como sustitución a la virtud antigua y a la cristiana, no deja de plantear la permanencia, desde fuera y desde dentro de los propios teóricos de la sociedad comercial, de la posibilidad de que el comercio pudiera llegar a corromper «les moeurs pures», que ya había señalado Montesquieu. La corrupción estaba allí, desafiando la deriva comercial de la Europa moderna:

What he seems to be saying [Montesquieu] is that in the social state based on Exchange, moeurs are already less than pures, which means that politics and moral have a quarrel with history, in which alone they can exist but in which they can never be free from corruption. Diderot, and of course Rousseau, would develop this paradox in several ways ${ }^{58}$.

Y, si bien es cierto que el ideal de libertad de los antiguos fue sustituido por la libertad de los modernos, también desde Montesquieu hasta Rousseau se desarrolló el reconocimiento de que la obtención de la libertad moderna impli-

${ }^{56}$ POCOK, 2018: 270.

57 Primera edición anónima en 1770, segunda, en 1774, tercera y definitiva, con autor, en 1780. POCOCK, 2005: 227 y ss.

${ }^{58}$ POCOCK, 2018: 274. 
caba el pago de un precio. «Corruption, Gibbon once remarked, was the infalible symptom of constitutional liberty» ${ }^{59}$.

Pocock es, así, bien consciente de la «ambivalencia» sobre la que se basa la propia sociedad comercial. Y, de paso, nos informa también de la consciencia que de la misma tenían los autores que trataban de ella, desde Hume, hasta Smith, desde Melon a Saint-Lambert o Didérot.

El gran difusor de este concepto de «ambivalencia» en un sentido profundamente técnico es Anoush Terjanian, quien se cuenta, además, entre los críticos de la «teoría del doux commerce», pero con unas matizaciones que consideramos de verdadero provecho ${ }^{60}$. Desde un principio nos señala que la intención de su obra consiste en exponer el papel clave de la «ambivalencia» en el pensamiento francés del siglo XVIII acerca del comercio. Para él, «ambivalencia» es una categoría que toma de manera genérica del psicoanálisis y que presupone el simultáneo odio y amor al mismo objeto o fenómeno. Su incorporación al discurso del comercio tendría la virtualidad, según nuestro autor, de equilibrar un discurso que ha sido prevalentemente analizado como unánimemente triunfante. Existiría así «un doux commerce» pero al mismo tiempo un «commerce odieux», elementos ambos de un mismo discurso: el discurso del comercio en el XVIII francés. Pese a diferencias con el autor en otros aspectos, consideramos sumamente útil esta apreciación para el estudio de la sociedad comercial y la comprensión que también tenían los contemporáneos de su misma complejidad. Alguien poco sospechoso de denostar el comercio como el mismo François Melon ya nos advertía, en la primera parte de su conocido Éssai, de la posibilidad de guerra en un mundo comercial de resultas de su funcionamiento interno. En el conocido supuesto que allí nos presenta de tres islas como los únicos territorios en el mundo, no deja de apuntar a la búsqueda de superioridad y al «condere leges» que alguna de ellas pudiera desarrollar. Incluso, aun siguiendo las recomendaciones que el mismo autor ofrece para el mejor desarrollo del comercio, de sus «principios esenciales»:

... une Isle rompra bientôt la balance rompra bientôt l'égalité bientôt la balance d'égalité, parviendra à la supériorité de puissance, \& donnera des loix aux autres Isles ${ }^{61}$.

Era algo que también percibieron y comprendieron perfectamente los intelectuales hispanos de la época. Juan Enrique Graef en sus Discursos Mercuriales que, según Jesús Astigarraga, eran traducción de escritos del Journal

59 POCOCK, 2018: 275 .

60 TERJANIAN, 2013.

${ }^{61}$ MELON, 1736: 9. Publicado en 1734 por vez primera, fue la segunda edición de 1736, corregida y con adición de siete capítulos, la que le otorgó una reconocida fama en el conjunto de Europa.

Hispania, 2021, vol. LXXXI, n. ${ }^{\circ}$ 269, septiembre-diciembre, págs. 651-681, ISSN: 0018-2141, e-ISSN: 1988-8368 https://doi.org/10.3989/hispania.2021.016 
Oeconomique $e^{62}$ y pueden reputarse por un verdadero ejercicio de «emulación», nos alertaba de las contradicciones morales que el comercio podía acarrear. El autor, que no tenía empacho en señalar que en el «comercio hay virtud», nos refería el peligro de que el comercio, incluso en el caso de un éxito inicial como fue el de la América Hispana, resultara en la extensión de un lujo no admisible $\mathrm{y}$, sobre todo, en la caída generalizada en el ocio, con desprecio final del mismo comercio, lo que era realmente una enorme desventaja en la Europa del momento ${ }^{63}$.

Creo, por último, que Istvan Hont en una obra postuma ${ }^{64}$ nos ofrece una clave conceptual para aclarar lo que aquí entendemos por "sociedad comercial». En un trabajo en el que compara de una forma nada habitual las obras de Smith y Rousseau y en el que propone una lectura en la que ambos aparecen como teóricos de la sociedad comercial, incorpora la definición que el mismo Adam Smith hace de dicha sociedad comercial. Su carácter general y su vinculación con aspectos morales, de sociabilidad general, además de económicos, nos resulta ciertamente útil en nuestra investigación, especialmente a los efectos comparativos con las concepciones y adaptaciones propias de los ilustrados hispanos.

Hont nos señala que Hirschman habría sugerido ya que estas cuestiones de las que venimos tratando deben ser comprendidas en un lenguaje maquiaveliano o de «razón de Estado», como el que resultaba de la contraposición entre pasiones e intereses. Siempre según Hont, tal sugerencia implicaría que la «sociedad comercial» habría de desenvolverse en una suerte de marco conceptual basado en el contraste y oposición entre utilidad y orgullo. Una verdadera sociabilidad habría de estar constituida por una tercera opción. En lugar de pasiones contra intereses debería ser cuestión de una interacción entre utilidad y «amor propio». Esto sería la «ungesellige Geselligkeit» de Kant, la sociabilidad insociable. Y esto es precisamente lo que Adam Smith considera que es la sociedad comercial, la forma de sociabilidad que el hombre, tal como es y en efecto, puede desarrollar ${ }^{65}$.

En su Teoría de los Sentimientos morales, cuyo tema central Hont, en otro trabajo, considera que es la moralidad artificial del hombre en un mundo comercial $^{66}$, señala tres formas de sociedad: la del amor, la del miedo y la de la utilidad. Entre la sociedad «perfecta» fundada sobre el amor y la basada en el miedo (que no puede finalmente subsistir) Smith introduce, así, un tercer tipo:

62 ASTIGARRAGA, 42/1 (Madrid, 2017): 239-260.

${ }^{63}$ GRAEF, 1996a; 1996b: 184-185.

${ }^{64}$ HONT, 2015.

${ }^{65}$ HONT, 2015: 13.

${ }^{66}$ «Economic competition was the subject of the Wealth of Nations, whereas the artificial morality of commercial man was the central theme of the Theory of Moral Sentiments», HONT, 2005: 50-51. 
But though the necessary assistence [entre todos los miembros de la sociedad] should not be affored from such generous and desinteresed motives, though among the different members of society there should be no mutual love and affection, the society though less happy and agreeable, will not necessarily be disolved. Society may subsist among different men, as among different merchants, from a sense of its utility, without any mutual love or affection; and though no man in it should owe any obligation, or be bound in gratitude to any other, it may be still upheld by a mercenary exchange of good offices according to an agreed valutation ${ }^{67}$.

Y será en la Riqueza de las Naciones donde Smith designe «sociedad comercial» a esta forma de constituirse la sociedad civil ${ }^{68}$. No queremos con esto significar «influencia» smithiana necesaria entre los pensadores ecónomicos y, particularmente, ilustrados hispanos del siglo XVIII, algo que ha sido descartado, o al menos fuertemente matizado, hace tiempo ${ }^{69}$, sino señalar que es un buen punto de partida para conocer las discusiones y posiciones hispanas de los intelectuales del siglo XVIII. Y que es a ello a lo que nos referimos al hablar de sociedad comercial y de «interés» $\mathrm{O}$ «amor propio» entre tales pensadores.

\section{Climent}

Tras este paseo historiográfico, volvemos a nuestro obispo, Joseph Climent i Avinent. Y con él, a su carta pastoral incluida al frente de la traducción de la obra de Fleury Des Moeurs des Israélites ${ }^{70}$. Y como ya indicamos, a nuestro entender la primera parte de la carta encaja perfectamente en la definición de «catolicismo ilustrado» en lugar de «Ilustración católica». A lo largo de toda la carta, en múltiples ocasiones, así como en el resto de sus obras, nuestro autor no deja de transmitirnos la suposición de fondo de que lo que ha de pretenderse es la necesaria «reforma de la Iglesia», de su disciplina y de su incidencia en las costumbres de los cristianos con la vuelta, adaptada a los tiempos, a los presupuestos de la Iglesia primitiva. Su episcopalismo, su consideración de la condición «iure divino» de los obispos, su intención de recuperación de los concilios y sínodos provinciales, su pretensión de restauración de la jurisdicción episcopal sobre el clero regular y las órdenes, su insistencia en el establecimiento de una educación primera en manos de la propia Iglesia y sus posiciones respecto de los padres y los teólogos a seguir (destaca la presencia reiterada de Santo

${ }^{67}$ SMITH, 1976b: 85-86. Sigo, en las indicaciones, a HONT, 2015: 9.

${ }^{68}$ HONT, 2015: 10. SMITH: 1976a: 37.

${ }^{69}$ PERDICES DE BLAS, 1999, vol. IV: 269-303. SCHWARTZ, 1999, vol. IV: 171-238. LLOMBART, 4/2 (Madrid, 2017): 147-156. HERNÁNDEZ ANDREU, 2 (Madrid, 2015): 109-121.

${ }^{70}$ FLEURY, 1771. 
Tomás y de San Agustín), reman en esa dirección. La vuelta a una Iglesia primitiva que era «pobre de bienes y rica de virtudes» $\rangle^{71}$. Al referirse a la cuestión de los diezmos, de cuya restitución en su totalidad a la Iglesia era partidario, lo exponía con claridad: «[...] y para decirlo de una vez [lo que se precisa es] el restablecimiento de la antigua disciplina» ${ }^{72}$.

Sin duda, el obispo había gozado de un ambiente intelectual renovador desde su etapa en Valencia, estaba al tanto de las corrientes novedosas europeas y había sabido incorporarlas a su discurso en lo que interesara al mismo. Pero siempre el fin sustancial era el de una reforma «within the Church.» Incluso podría señalarse que cubría casi a la perfección los pasos que Bernard Plongeron habría considerado característicos de la Aufklärung católica. Pero no se trataba, como tampoco lo que Plongeron nos proponía, en nuestra opinión, de «Ilustración católica», por mucho «catolicismo ilustrado» que contenga ${ }^{73}$.

Una posición, la de nuestro autor, que ya habría comenzado por proponer la abnegación y la renuncia a los bienes de este mundo ${ }^{74} \mathrm{y}$, con ello, el control de las pasiones, control que se dejaba percibir con mayor claridad en la diatriba contra el lujo que forma el núcleo de lo que podríamos denominar una segunda parte de la carta. Repárese que ya establecimos que el lujo a estas alturas está íntimamente conectado a las cuestiones relacionadas con la sociedad comercial. Istvan Hont, en un trabajo ya citado en el que repasa las discusiones de radio europeo acerca del lujo, viene a señalar que tales discusiones se enmarcan en dos contextos distintos y, como tales, analizables de forma diferente. Por un lado, una discusión del tipo ancients vs modernes. En este caso, la cuestión resultaría de la posición absolutamente negativa de cristianos y republicanos respecto del lujo. Por otro, una suerte de discusión interna a los propios modernes. Aquí no se trata de aceptar o no el mundo de la sociedad comercial, sino de cómo convertirlo en algo que fuese política y moralmente bueno ${ }^{75}$. En este caso, se trataría de una discusión entre los partidarios de un lujo sin regulaciones y un lujo «bien ordenado».

Resultaría difícil colocar a nuestro buen obispo entre estos segundos. La suya es la posición de un ancient, en este sentido, de un cristiano (católico) que se apropia para sus propios fines de partes del discurso republicano, algo habitual entre los autores cristianos más refractarios respecto de la sociedad comercial $^{76}$.

${ }^{71}$ CLIMENT, 1771: XXX.

${ }^{72}$ CLIMENT, 1771: XLII.

${ }^{73}$ PLONGERON, 16/4 (París, 1969): 555-605.

${ }^{74}$ CLIMENT, 1771: XVIII.

75 HONT, 2006: 380.

${ }^{76}$ Smidt lo considera un verdadero republicano, lo que no compartimos. Véase FERNÁNDEZ ALBALADEJO, 42/2 (Madrid, 2002): 662-667. 
Empezando ya por su misma definición del lujo, («y verdaderamente siendo como es el lujo un exceso en la comida, bebida, vestido, adorno y diversiones...»), que reproduce la definición tradicional. La posición se hace tanto más clara cuando observamos definiciones del lujo que se apartan de ese camino para intentar ajustarse más a los términos de la «modernidad» comercial. SaintLambert, nos pone en la pista precisamente al cambiar tal definición tradicional. «LUXE, [señala], c'est l'usage qu'on fait des richesses \& de l'industrie pour se procurer une existence agréable» $\rangle^{77}$. El cambio tendría fuertes implicaciones. Este giro suponía la conversión del lujo en una parte constitutiva del «amor propio», «a direct offspring of human instinct», una definición que se convertiría en familiar a partir de su consideración en la Riqueza de las naciones de Adam Smith como «the desire of bettering our condition, a desire which, though generally calm and dispassionate, come with us from the womb and never leaves us till we go into the grave ${ }^{78}$. La clave de una tal definición, desde un punto de vista filosófico, residía en hacer del «amor propio» un elemento positivo en la sociabilidad humana ${ }^{79}$.

Nada más alejado de lo que, respecto del lujo y, como vemos, por implicación, de la «sociedad comercial», nos ofrecía el obispo de Barcelona. No es de extrañar que de ello resultara una apreciación del lujo como algo que resultaba «intrinsecamente malo à la luz de la razón» ${ }^{80}$. De manera que el lujo se concibe como vicio en sí mismo, en su esencia. Un vicio que, si ya es dañino en lo que se refiere a los particulares, es perniciosísimo cuando llega a «inficionar» a una nación «porque son inseparables compañeras suyas la vanidad, la lujuria, la afeminición, y una general corrupción de las costumbres» ${ }^{81}$. El innegable sabor republicano venía, así, en auxilio de las pretensiones indudablemente católicas de nuestro autor. Desde tales planteamientos la posibilidad de una conjunción del lujo con un amor propio que pudiera resultar positivo desaparecía radicalmente. Y el amor propio, el interés, era el motor de la sociedad comercial.

Por supuesto, para Climent, detrás de todo ello se encontraba la «falsa filosofía» o «filosofismo moderno», a cuya irrupción había contribuido notablemente también la «libertad de opinar sin respeto a la Sagrada Escritura, ni a la Tradición, ò el probabilismo» que no tienen en cuenta la corrupción que experimentó la naturaleza humana y cuyos defensores ponen sus pasiones como

77 SAINT-LAMBERT, 1765, tomo IX: 763b-771b. El artículo aparecía, como indicamos, en 1765 pero se hallaba ya impreso en 1764. La definición del lujo es deudora del artículo «Du Luxe», publicado en 1754 en sus Éléments du commerce por Forbonnais, aunque con alguna modificación. Véase MOUREAU, I (París, 1986): 71-84. El artículo de SaintLambert fue erróneamente atribuido durante mucho tiempo a Diderot.

${ }_{78}^{78}$ Las citas, reproducidas en HONT. 2006: 379-380

79 HONT, 2006: 380.

${ }^{80}$ CLIMENT, 1771: XLIII- XLIV. La cursiva es mía.

${ }^{81}$ CLIMENT, 1771: XLIV. 
medida de sus acciones. La cuestión no era tanto la crítica a esa «falsa filosofía», que en la época resultaba habitual, incluidos aquellos ilustrados hispanos que aceptaron la posibilidad de compatibilizar «amor propio», «sociedad comercial» y catolicismo. En el caso de nuestro autor, lo que realmente contaba era la necesidad de control de las pasiones. En efecto, la vida verdaderamente cristiana (que era la de los primeros fieles, todo tenía su conexión) consistía en limpiar los pecados con la penitencia y «precaverse para no cometerlos con la mortificación de las pasiones, y un continuo ejercicio de las virtudes» ${ }^{82}$. El lujo resultaba, así, «un desenfreno en las pasiones y un agregado de los vicios de gula, vanidad, lujuria, y singularmente de prodigalidad que es un vicio perniciosisimo al Estado» ${ }^{83}$. Pese a ello no dejan de aparecer autores que juzgan útil el vicio de la prodigalidad porque entienden que eso hace circular los caudales en la república, particularmente los caudales de los ricos. Pero, a los ojos de nuestro autor, esto no hace sino que dichos caudales corran hacia destinos impropios y, en lo que se refiere a la Monarquía Hispánica, «los dineros de los pródigos van a los extranjeros $\rangle^{84}$. Insertos como nos hallamos en los esquemas tradicionales de la virtud cristiana, no había, así, lugar para las apreciaciones propias de una «sociedad comercial» sustentada en la sociabilidad que implicaban los hábitos y las costumbre. De manera que, al lujo, y la sociedad que implica, se le acaba por atribuir toda suerte de males que afectan a las sociedades, pasadas y presentes. Lo sabía todo el mundo y lo acreditaba la experiencia de todos los siglos: «El lujo, y la lujuria, fue la causa de la ruina de la Repúblicas y Monarquías» pero no es solo cuestión de un pasado más o menos remoto, pues, «ahora mismo, vemos que aquellas Naciones que subministran las modas profanas, y los instrumentos de lujo à toda Europa, se afeminaron y perdieron el valor, y la gloria militar que adoptaron sus ascendientes ${ }^{85}$. Y ya por hacer responsable de todos los males al lujo, también sería responsable, a través de los «pretensos nuevos filósofos», de la introducción de un supuesto «derecho a la igualdad» sobre cuyo fundamento, además, habrá de destruirse la soberanía real. Y ello, como no podía ser de otra manera, proviene del hecho de que tales filósofos impostores, los seguidores de esta «secta», o son «atheistas y materialistas» o «deístas», lo que les hace peores que los herejes por cuanto la «incredulidad» o la irreligión que expanden causa mayores estragos que aquella, aunque afortunadamente «...nuestra España se conserva libre de esta peste» pero no exenta del peligro pues «...no dejan de oírse algunas voces impías de algunos jóvenes que por su desgracia en países extrangeros leyeron los perver-

${ }^{82}$ CLIMENT, 1771: LI.

${ }^{83}$ CLIMENT, 1771: LI.

${ }^{84}$ CLIMENT, 1771: LI.

${ }^{85}$ CLIMENT, 1771: XLVII. 
sos libros, que publican los maestros, ò pregoneros de la impiedad $»^{86}$. La crítica que el obispo había realizado a las supersticiones modernas en el seno de una Iglesia, en ese campo, alejada de la pureza primitiva no era incompatible con la correspondiente crítica a la moderna irreligión.

Por otro lado, como ya señalamos, la denegación del carácter siquiera útil del lujo implicaba una denegación también de la propia «sociedad comercial.» Y de ello nos daba cumplidas muestras el escrito que venimos analizando. Detrás del lujo estaba la «sociedad comercial». Algo ya hemos podido apreciar al referirnos a la circulación de caudales. Pero había más, incluso más claro:

Según parece, los que defienden ser el lujo útil à la sociedad, suponen que los hombres precisamente han de ser avaros, ò prodigos, y que más vale que sean prodigos que avaros: como si ya no quedára en el mundo rastro de las virtudes de la liberalidad, y misericordia; como si los hombres ya no pudieran ser liberales, y misericordiosos, y expender sus bienes según mandan la lei natural, y la ley Evangélica. ¡Bárbaro modo de pensar que despoja al hombre de la humanidad! ${ }^{87}$

Era la «caritas» como núcleo sustancial de la sociedad frente al interés, al «amor propio».

\section{DisCUSIONES COMERCIALES}

A estas alturas, en el ámbito de la Monarquía Hispánica se contaba no solo con una tradición de discusión acerca del lujo enmarcada, generalmente, en las consideraciones de diferentes autores sobre el «amor propio» o el comercio ${ }^{88}$. Además, se disponía de la presencia de la obra probablemente más importante y difundida acerca de dicha cuestión: el Éssai de Melon ${ }^{89}$. Venía, en gran medida, bajo la forma de traducción, aunque se pretendía hacer pasar por obra propia. Se trataba de una obra de Argumosa Gándara que, en realidad, resultaba una adaptación, con mucha carga de literalidad, a las circunstancias culturales hispanas ${ }^{90}$.

Sobre todo, nos interesan las modificaciones llevadas a cabo para mejor adaptación a la peculiaridad católica de dicha monarquía ${ }^{91}$. En efecto, como

${ }^{86}$ CLIMENT, 1771: XLIX

${ }^{87}$ CLIMENT, 1771: LII.

${ }^{88}$ FERNÁNDEZ ALBALADEJO, 46/1 (Madrid, 2021): 9-29. VIEJO, 2006: 73-92. Por supuesto, la discusión acerca del «amor propio» constituía un tópico en la teología y la filosofía tradicionales y, por su vía, en el derecho.

${ }^{89}$ MELON, 1734.

${ }^{90}$ ARGUMOSA GÁNDARA, 1743. ASTIGARRAGA, 57/1 (París, 2010): 91-118.

91 ASTIGARRAGA, 57/1 (París, 2010): 98. 
decimos, la traducción, como era por lo demás habitual en la época ${ }^{92}$, resultaba una adaptación. Pero ya nos introducía en algo significativo: era posible la adopción del discurso del lujo sin que ello entrara en contradicción con la catolicidad hispana. De hecho, traducciones posteriores en las que se insertaban aspectos relacionados con el lujo, no dejarán de proceder en la misma dirección. Incluso nuevas versiones del mismo Éssai. Lorenzo Normante, que publicaba, en 1786, un Espíritu del Señor Melon ${ }^{93}$, precisamente en un momento de máxima recepción de los tratados económicos provenientes de Europa, se encontraba entre ellos. La traducción hace además su aparición en el marco de la «Cátedra de Economía civil y de comercio» de Zaragoza, la cual había sido fundada por la Sociedad Económica Aragonesa de Amigos del País en 1784 y de la que Normante fue su primer titular ${ }^{94}$.

Precisamente, en el capítulo dedicado al lujo, alteración mediante del orden expositivo del Éssai, Normante encontraba mejor salida a sus propias consideraciones. Refiriéndose a las «vanas declamaciones» que sobre el mismo se habían hecho, señalaba:

Hablamos solamente de aquellas vanas declamaciones que caminan por principios distintos de los de nuestra Religion Christiana, y que no se conforman con la debilidad de nuestra naturaleza ${ }^{95}$.

Sin embargo, no encontraba el traductor contradicción alguna entre esta afirmación y otras posteriores en las que indicaba que las pasiones son las que (eso sí, por desgracia) dirigen nuestras acciones, que el militar solo es valiente por ambición, el negociante se afana por codicia y ambos se mueven por conseguir disfrutar «de las cosas de luxo, esto es, de vivir con especial comodidad y recreo». Así, llamaba a «que los Legisladores seculares no se fixen precisamente en desterrar las pasiones, lo que nunca podrán conseguir, sino que procuren sacar la posible utilidad de las mismas, convirtiéndolas ácia los objetos ventajosos $\gg{ }^{96}$. Y no se trataba solo de la afirmación de una naturaleza humana que era así y no cabía otro remedio. Latía un posicionamiento positivo general, como en el propio Éssai. Normante había colocado al principio del capítulo la definición de lujo y su proveniencia, que en la obra de Melon aparecía unos párrafos más tarde. Y así se nos señalaba de entrada:

${ }_{92}$ Para unos conceptos de autor, autoridad o plagio que eran totalmente diversos de los de la época actual, BECK, 47 (2017): 252-277.

${ }_{93}$ NORMANTE, 1984.

${ }^{94}$ Para Normante, la Sociedad Aragonesa de amigos del País, y la citada cátedra y las campañas contra la misma, véase PEIRÓ, 1984: 13-32.

95 NORMANTE, 1984: 37.

96 NORMANTE, 1984: 37. 
El luxo, que consiste en una cierta suntuosidad proporcionada por las riquezas y seguridadd del Gobierno, y que es una conseqüencia de la cultura de toda Nacion polizada... ${ }^{97}$

Un luxo «bueno» era así posible. La conjunción de lujo y confesión católica se abría paso. Y con ello, dada la asimilación que ya hemos referido entre lujo y sociedad comercial, cabía una defensa de esta en tanto que fuese compatible con dicha confesión católica. Era esto era precisamente lo que Josef de Cabra reprochaba a nuestro autor ${ }^{98}$. La conjunción entre sus abiertas declamaciones católicas y la defensa del «vicio del lujo» especialmente tratándose de un católico hispano ${ }^{99}$. Esta será, para nosotros, la característica fundamental de una ilustración hispana, como venimos indicando. Pero no adelantemos acontecimientos. Sigamos por esta vía del lujo, de momento.

En la primera traducción de los Discursos de Hume que tuvo lugar en España y que data de 1789, el anónimo traductor nos advertía de que un lector atento echará en falta la presencia de cuatro «discursos» que sí se hallan presentes en la traducción francesa que se sigue. Una traducción al francés destaca sobre todas las otras tanto por su abundancia de ensayos traducidos, como por su éxito editorial y, además, por una cuantiosa presencia de paratextos al servicio de la difusión del proyecto económico, moral y social del círculo formado en torno a Vincent de Gournay. La realizaba el abad Jean-Betrand Le Blac y se publicó en Amsterdam, en 1754. Pero, a pesar de que los estudiosos suelen confundir esta edición con la del mismo año y lugar, realizada por Éléazar de Mauvillon (mucho menos conocida en la época y ahora), es esta la que encaja a la perfección con esa falta de cuatro discursos que nos señala el traductor ${ }^{100}$. Detrás de ella había más que una pura declaración de incapacidad o de falta de disposición. En realidad, lo que se ocultaba era la imposibilidad de llevar a cabo una traducción «adecuada» de los cuatro ensayos que faltaban por cuanto su incompatibilidad con la confesión católica se hallaba sumamente repartida entre ellos, de manera que prepararlos para la impresión en España era prácticamente imposible ${ }^{101}$. Si se analizan detenidamente, además, los Discursos

${ }_{97}$ NORMANTE, 1984: 36. En MELON, 1736: IX, 106, se señalaba: «Le Luxe est une somptuosité extraordinaire que donnent les richesses \& la securité d'un gouvernement; c'est une suite nécéssaire de toute société bien policée».

${ }^{98}$ CABRA, 1787.

99 CABRA, 1787: 3 y ss.

100 MAUVILLON, 1754. LOÏC, 2008: 182-202, 201. LLOMBART, 21 (Florencia, 2017-2018): 1123-1702. El autor señala una traducción francesa de 1754, en Amsterdam, y las ediciones de Dresde, 1754, Amsterdam, 1767 y París-Lyon, 1767.

${ }^{101}$ Los Discursos eran, siempre en su traducción francesa, «Sur quelques Coutumes remarquables», «Sur le nombre d'habitants parmi quelques nations anciennes», «Sur la succession Protestante», «Idée d'une Republique Parfaite». 
efectivamente «traducidos» podemos afirmarnos en tal indicación por cuanto estos se hallan trufados de adaptaciones que permitan recibir las posiciones acerca del lujo y de la sociedad comercial en un universo cultural e institucional católico, que permitan conjugarlas con el mismo. Hemos de indicar, en primer lugar, que esta cuestión de la conjunción entre lujo, sociedad comercial y confesión católica no es necesariamente la posición de otros autores hispanos, dispuestos a incorporar presupuestos ilustrados de corte más «radical». A este respecto, no se puede dejar de mencionar el «Discurso sobre el lujo» de Manuel de Aguirre. Ciertamente, en él aparecía un lenguaje que se distanciaba de la posición, a nuestro entender mayoritaria dentro de la Ilustración hispana, con su compatibilización entre los presupuestos propios de una sociedad comercial y de su motor principal, el «amor propio». Su ensayo aparecía en el contexto de la Real Sociedad Bascongada de Amigos del País (1765). En 1776, era presentado ante la Real Sociedad que publicó un resumen en sus Extractos y que apareció completo (y anónimo) en el Correo de los ciegos de Madrid, en 1787. Aunque, en sustancia, el ensayo acababa por afirmar la existencia de un lujo moderado frente a un lujo excesivo y reprobable, es cierto que introducía un lenguaje con un sabor bastante más radical de lo que parecía soportable en el seno de la monarquía. Probablemente, de resultas de la presencia no visible de Hume tras el escrito. Jesús Astigarraga ha descrito a la perfección tales planteamientos de Aguirre, las denuncias que hubo de sufrir ante la Inquisición tanto en su primera aparición, como tras su publicación en 1787, en el contexto de las denuncias del capuchino José de Cádiz contra la Bascongada ${ }^{102}$. En 1790 este segundo expediente condujo a su condena inquisitorial, probablemente dada la inserción en el momento de cierre producido tras los acontecimientos de 1789 en Francia.

Sin desconsiderar tales posiciones menos comprometidas con los intentos de compatibilización ya reiterados, a nuestro entender, y no solo, no principalmente, por causa de censura, esta última posibilidad resultó, a la postre, mayoritaria entre los ilustrados hispanos.

\section{LUJO, INTERÉS, SOCIEDAD COMERCIAL Y CONFESIÓN CATÓLICA}

En 1788 aparecía la conocida Historia del lujo y de las leyes suntuarias ${ }^{103}$, de Sempere y Guarinos. El lujo que, según este autor, pudiera resultar algo rechazable (incluso podría considerarse un vicio) desde una perspectiva abstracta se nos presenta, sin embargo, como producto de la sociedad, en su dimensión más concreta. Lo ha habido en todas las épocas y, muy especialmente, en

102 ASTIGARRAGA, 2003.

103 SEMPERE, 2000. 
la sociedad fundada en el comercio. De ello se presumía que el lujo era resultado de la civilización y la cultura. Además, era necesario en un mundo de «naciones» en competición, por cuanto estas lo permiten como forma de incrementar su riqueza, sus artes, sus invenciones... En definitiva, en la medida que pasamos de un planteamiento filosófico a otro histórico, el lujo pasaba, a su vez, de ser un vicio, sin más, a ser una suerte de vicio constitutivo de la sociedad civil. Ante el temor de que al verle «declamar contra las leyes suntuarias» se pudiera pensar que era un defensor sin más del lujo, nuestro autor señalaba que reconocía todos los daños «morales y civiles que produce en la sociedad» pero:

... demuestro que este vicio resulta inevitable en las sociedades civiles en donde vivimos y con las que tenemos comunicación [...]. Y que en el estado actual no debe tratarse tanto de destruirlo cuanto de hacerlo menos dañoso ${ }^{104}$.

Y no dejaba, a su vez, nuestro autor de señalar la correspondiente conexión entre lujo y «sociedad comercial» ${ }^{105}$. Al efecto de aclarar más sus proposiciones, incluía dos capítulos específicamente dedicados a la moral y a la política en relación con el lujo. Y, si ya desde la dedicatoria de la obra a Floridablanca ${ }^{106}$ el autor nos recordaba que la diversidad de opiniones acerca del lujo «proviene principalmente de no unirse la erudición y la filosofía con la religión», en los dos capítulos referidos explicitaba aún más esa forma de adecuación y nos indicaba que sus reflexiones se realizaban no por principios arbitrarios o tomadas de autores sospechosos, «sino con arreglo a las máximas más puras de nuestra Sagrada religión». Y así es, en efecto, por cuanto parte tanto en una como en otra reflexión de la Summa de Santo Tomás. De ella, finalmente, deducirá la existencia de un lujo ordenado y otro desordenado, de uno vicioso y otro inocente. Y en caso de la no existencia de prescripción por la «constitución civil» de los límites entre uno y otro, la regla principal para distinguirlos consiste en examinar los afectos y fines que «mueven el corazón» ${ }^{107}$. Finalmente, el lujo (no vicioso) era, a pesar de las ambivalencias que el autor no deja de reconocer en todo el escrito, útil al «Estado». Y como los «legisladores» conocen a la perfección que los «hombres obran, generalmente, no por la virtud, sino por su interés y la vanagloria», deben servirse de estos «para lograr el efecto principal de la legislación, que es la conservación del estado, la subsistencia y la tranqui-

104 Véase IÑURRITEGUI, 8/1 (2019): 10. SEMPERE, 2000: 75-76.

105 SEMPERE, 2000: 72.

106 SEMPERE, 2000: 69.

107 SEMPERE, 2000: 364. 
lidad pública por medio del trabajo, y la defensa de la nación por medio de las riquezas $\rangle^{108}$.

Lujo, sociedad comercial, interés y confesión católica. Sin muestra de incompatibilidad. Ahí residía, a nuestro entender, la clave de comprensión de una «ilustración hispana» en el seno de una monarquía que se consideraba católica «por constitución». Era algo que había detectado a la perfección Juan Pablo Forner. En sus Demostraciones palmarias ${ }^{109}$. Bajo el seudónimo del «Bachiller Regañadientes», el autor, desde el campo contrario a los defensores del lujo daba con la clave de la operación que venían realizando (y en la que no dejaran de insistir) los ilustrados hispanos. Particularmente frente al periódico El Censor señalaba que en unos discursos aparecidos en este periódico «intenta concordar el luxo con el Evangelio» ${ }^{110}$. Según Forner, Hume estaba detrás de dichos discursos, pero el autor de los mismos había tenido la habilidad de «introducir en su patria las máximas del libro inglés vistiéndolas a la española», esto es, habría deducido una «ambigüísima conformidad entre el luxo y el Evangelio ${ }^{111}{ }^{2}$. Como sabemos dos años después aparecía la traducción de los ensayos del autor escocés.

\section{Bibliografía}

Aguirre, Manuel de, Cartas del militar ingenuo al Correo de los Ciegos de Madrid. Precedido de sistema de Sociedades patrióticas y de seminario o casas de educación, edición de Antonio Elorza, San Sebastián, Gráficas Izarra, 1975.

Alimento, Antonella y Stapelbrock, Koen, The Politics of Commercial Treaties in the Eighteenth Century. Balance of Power, Balance of Trade, Londres, Palgrave MacMillan, 2017.

Argumosa Gándara, Teodoro Ventura de, Erudición política, y despertador sobre el comercio, agricultura y manufactura con avisos de buena política y aumento de Real Erario, Madrid, 1743.

Astigarraga, Jesús, Los ilustrados vascos. Ideas, instituciones y reformas económicas en España, Barcelona, Crítica, 2003.

Astigarraga, Jesus, «La dérangeante découverte de l'autre: traductions et adaptations espagnoles de l'Éssai politique sur le commerce de Jean-François Melon», Revue d'histoire moderne \& contemporaine, 57/1 (París, 2010): 91-118.

Astigarraga, Jesús (ed.), The Spanish Enlightenment revisited, Oxford, Voltaire Foundation, 2015.

108 SEMPERE, 2000: 372.

109 IÑURRITEGUI, 8/1 (2019). FORNER, 1787.

110 FORNER, 1787: 6. Sobre estos aspectos precisamente en los discursos del Censor sobre el lujo, VIEJO, 2018: 86 y ss.

111 FORNER, 1787: 25. 
Astigarraga, Jesús, "Oikonomia y "comercio" en la versión española del Journal Oeconomique: los Discursos Mercuriales de Graef», Cuadernos de Historia Moderna, 42/1 (Madrid, 2017): 239-260.

Astigarraga, Jesús y Usoz, Javier L'Économie Politique et la Sphère Publique dans le débat des Lumières, Madrid, Casa de Velázquez, 2013.

Beck, Laura, «Authorship in Early Modern Jurisprudence: Paul Voet (1619-1667) on auctor and editor». Quaerendo, 4 (2017): 252-277, en línea, doi 10.1163/1570069012341385.

Berg, Maxine y Eger, Elisabeth, Luxury in the Eighteenth Century. Debats, Desires and Delectable Goods, Basingtoke, Palgrave, 2003a.

Berg, Maxine y Eger, Elisabeth, «The rise and fall of the Luxury debates» in Maxine Berg y Elisabeth Eger, Luxury in the Eighteenth Century. Debats, Desires and Delectable Goods, Basingtoke, Palgrave, 2003b: 7-27.

Berry, Charles, The Idea of Luxury. A conceptual and historical investigation, Cambridge, Cambridge University Press, 1994.

Butterwick, Richard, «Between Anti-Enlightenment and enlightened Catholicism: provincial preachers in late eigteenth century Poland-Lituania» en Richard Butterwick, Simon Davies y Gabriel Sánchez-Espinosa (eds.), Peripheries of the Enlightenment, Oxford, Voltaire Foundation, 2008: 208-221.

Cabra, Gerónimo Joseph de, Pruebas del Espíritu del Sr. Melon y de las Proposiciones de Economía civil y comercio del Sr. Normante, Madrid, Isidoro Hernández Pacheco, 1787.

Charles, Loïc, «French "New Politics" and the dissemination of David Hume's Political Discourses on the Continent» en Charles Wennerlind y Margaret Schabas, David Hume's Political Economy, Londres, Routledge, 2008: 182-202.

Cheney, Paul, Revolutionary Commerce. Globalisation and the French Monarchy, Cambridge, MA, Harvard University Press, 2010.

Climent, José, "Carta», en Las costumbres de los israelitas escritas en francés por el Señor abad Claude Fleury... traducidas en Español por Don Martínez Pingarrón, Valencia, Agustín Laborda, 1771.

Climent, José, Colección de las Obras del Ilmo. Señor D. Joseph Climent, Madrid, Imprenta Real, 1788.

Fernández Albaladejo, Pablo, Fénix de España. Modernidad y Cultura propia en la España del siglo XVIII, Madrid, Marcial Pons, 2006.

Fernández Albaladejo, Pablo, «Reseña a M. Herrero Sánchez (ed.), Repúblicas y republicanismo en la Europa Moderna (siglos XV-XVIII), México, 2017», Cuadernos de Historia Moderna, 42/2 (Madrid, 2017): 662-667.

Fernández Albaladejo, Pablo, «Comercio redentor: arbitrismo peninsular y proyectismo atlántico en la Monarquía de España (1668-1675)» Cuadernos de Historia Moderna, 46/1 (Madrid, 2021): 9-29.

Fleury, Claude, Las costumbres de los israelitas escritas en francés por el Señor abad Claude Fleury... traducidas en Español por Don Martínez Pingarrón, Valencia, Agustín Laborda, 1771. 
Forner, Juan Pablo, Demostraciones palmarias de que el «Censor», su «Corresponsal», el «El Apologista Universal» y los demás papelejos de este jaez, no sirven de nada al Estado, ni a la Literaura de España, Madrid, Imprenta Real, 1787

Fuentes Quintana, Enrique (dir.), Economía y Economistas españoles, Barcelona, Galaxia Gutenberg / Círculo Lectores, 1999, IV vols.

Graef, Juan Enrique, Discursos Mercuriales Económico-Políticos (1752-1756), selección, introducción y edición de Francisco Sánchez-Blanco, Sevilla, Fundación El Monte, 1996a.

Graef, Juan Enrique, «Discurso sobre el comercio en general (1755)» en Discursos Mercuriales Económico-Políticos (1752-1756), selección, introducción y edición de Francisco Sánchez-Blanco, Sevilla, Fundación El Monte, 1996b: 179-181.

Hernández Andreu, Juan, «La Riqueza de las Naciones de Adam Smith en España», Relectiones, 2 (Madrid, 2015): 109-121.

Hirschman, Albert O., The passions and the interests: Political arguments for capitalism before its triumph, Princeton, Princeton University Press, 2013.

Hont, Istvan, Jealousy of Trade. International Competition and the Nation-State in Historical Perspective, Cambridge, MA, Harvard University Press, 2005.

Hont, Istvan, «The early Enlightenment debate on commerce and luxury» en Mark Goldie y Robert Wokler, The Cambridge History of Eighteenth Century Political Thought, Cambridge, Cambridge University Press, 2006: 379-418.

Hont, Istvan, Politics in Commercial Society. Jean-Jacques Rousseau and Adam Simith, en Béla Kapossy y Michael Sonenscher (eds.), Cambridge, MA, Harvard University Press, 2015.

Iñurritegui, José María, «Images of Baetica. The ambivalent hispanic reception of Les aventures de Télémaque», Culture \& History Digital Journal, 8/1 (Madrid, 2019): 1-14, doi: 10.3989/chdj.2019.013.

Kaposi, Béla, Nakhimovsky, Isaac, Reinert, Sophus y Whatmore, Richard, Markets, Morals, Politics. Jealousy of Trade and the History of Political Thought, Cambridge, MA, Harvard University Press, 2018.

Lafrance, Xavier, The Making of Capitalism in France. Class Structures, Economic Development. The State and the formation of the French Working Class, 17501914, Leiden, Brill, 2019.

Llombart, Vicent, «Jovellanos y Adam Smith. Acerca del fenómeno de las influencias en la historia del pensamiento económico», Iberian Journal of the History of Economic Thought, 4/2 (Madrid, 2017): 147-156.

Llombart, Vicent, «Nuevo Catálogo de traducciones de economía al y del castellano», Cromhos, 21 (Florencia, 2017-2018): 1123-1702.

Mauvillon, Éléazar, Discours politiques de Mr. David Hume, traduits de l'Anglois par $M r$. De $M^{* * * *}$, Amsterdam, J. Schreuder \& Pierre Mortier le jeune, 1754.

Melon, Jean- François, Éssai politique sur le commerce, seconde édition augmentée de sept chapitres \& oú les lacunes des éditions précedentes sont remplies, s.1., s.e., 1736. [1734].

Mestre, Antonio, «José Climent. Un obispo acusado de Jansenista» en Estela Callado (coord.), Valencianos en la Historia de la Iglesia, Valencia, Facultad de Teología San Vicente Ferrer, 2009, vol. III: 197-236. 
Moureau, François, «Le manuscrit de l'article Luxe ou l'atelier de Saint-Lambert», Recherches sur Diderot et sur L'Encyclopédie, I (París, 1986): 71-84.

Normante, Lorenzo, Espiritu del señor Melon en su Ensayo político sobre el comercio, edición de Antonio Peiró, Zaragoza, Diputación General de Aragón, 1984.

Peiró, Antonio, «Burguesía, Ilustración y análisis económico: Lorenzo Normante y la Cátedra de Economía Civil y Comercio», en Lorenzo Normante, Espiritu del señor Melon en su Ensayo político sobre el comercio, Zaragoza, Diputación General de Aragón, 1984: 13-32.

Perdices de Blas, Luis, «La "Riqueza de las Naciones" y los economistas españoles» en Enrique Fuentes Quintana (dir.), Economía y Economistas españoles, Barcelona, Galaxia Gutenberg / Círculo de Lectores, 1999, vol. IV: 269-303.

Plongeron, Bernard, «Recherches sur "l'Aufklärung" catholique en Europe occidentale (1770-1830)», Revue d'Histoire Modèrne et Contemporaine, 16/4 (París, 1969): 555-605.

Pocock, John, The Machiavellian Moment. Florentine Political Thought and the Atlantic Republican Tradition, Princeton, Princeton University Press, 1975.

Pocock, John, «The Mobility of property and the rise of eighteenth-century sociology» en Virtue, Commerce, and History. Essays on Political Thought and History, Chiefly in Eighteenth Century, Cambridge, Cambridge University Press, 1985: 103-123.

Pocock, John, Barbarism and Religión, Cambridge, Cambridge University Press, (1999-2015), 6 vols.

Pocock, John, Barbarism and Religion, Barbarians, Savages and Empires, Cambridge, Cambridge University Press, 2005, vol. IV.

Pocock, John, «Perceptions of Modernity in Early Modern Historical Thinking», Intellectual History Review, 17/I (Londres, 2007): 55-63.

Pocock, John, «Commerce, Credit, and Sovereignty. The Nation-State as Historical Critique» Béla Kaposi, Isaac Nakhimovsky, Sophus Reinert y Richard Whatmore, Markets, Morals, Politics. Jealousy of Trade and the History of Political Thought, Cambridge, MA, Harvard University Press, 2018.

Reinert, Sophus, «Lessons on the Rise and fall of the Great Powers: Conquest, Commerce, and Decline in Enlightenment Italy», American Historical Review, 115/5 (Chicago, 2010): 1395-1425.

Reinert, Sophus, Tranlating Empire. Emulation and the origins of political economy, Cambridge, MA, Harvard University Press, 2011.

Robertson, John, The case for the Enlightenment. Scotland and Naples, 1680-1760, Cambridge, Cambridge University Press, 2005.

Robertson, John, «Enlightenment, public sphere and political economy», en Jesús Astigarraga y Javier Usoz, L'Économie Politique et la Sphère Publique dans le débat des Lumières, Madrid, Casa Velazquez, 2013.

Rousselière, Geneviève, «Reseña a Reinert, Sophus, Translating Empire», Review of Politics, 74/3 (Cambridge, 2019): 530-33.

Saint-Lambert, marqués de, «Luxe», en Robert y Roe Morrissey (eds.), L'Encyclopédie, 1765, tomo IX: 763b-771b, disponible en https:// artflsrv03.uchicago.edu/philologic4/encyclopedie0521/query?report=bibliogra phy\&method=proxy\&attribution $=\&$ objecttype $=\&$ start $=0 \&$ end $=0 \&$ head $=$ luxe 
Schwartz, Pedro, «La recepción inicial de la "Riqueza de las Naciones" en España», en Enrique Fuentes Quintana (dir), Economía y Economistas españoles, Barcelona, Galaxia Gutenberg / Círculo Lectores, 1999, vol. IV: 171-238.

Sempere y Guarinos, Juan, Historia del lujo y de las leyes suntuarias de España, edición de Juan Rico Jiménez, Valencia, Alfons el Magnànim, 2000. [1788].

Shovlin, John, The Political Economy of Virtue. Luxury, Patriotism, and the Origins of the French Revolution, Ithaca, Cornell University Press, 2006.

Shovlin, John, «Hume's Political Discourses and the French luxury debate», en Charles Wennerlind y Margaret Schabas, David Hume's Political Economy, Londres, Routledge, 2008: 203-222.

Smidt, Andrea, «Piedad e ilustración en relación armónica. Josep Climent i Avinent, obispo de Barcelona, 1766-1775», Manuscrits, 20 (Barcelona, 2002): 91-109.

Smidt, Andrea, Fiestas and fervor: religious life and catholic enlightenment in the Diocese of Barcelona, 1766-1775, Columbus, Ohio, Ph. D. School of the Ohio State University, 2006.

Smidt, Andrea, «Luces por la Fe: The Cause of Catholic Enlightenment in 18th-century Spain» en Ulrich L. Lehner y Michael Printy Lehner (eds.), A Companion to the Catholic Enlightenment in Europe, Leiden, Brill, 2010: 403-452.

Smith, Adam, An Enquiry into the Nature and Causes of the Wealth of Nations, edited by Roy Harold Campbell y Andrew Skinner, Oxford, Oxford University Press, 1976a.

Smith, Adam, The Theory of Moral Sentiments, edited by David Daiches Raphael y Alexander Lyon Macfie, Oxford, Oxford University Press, 1976b.

Terjanian, Anoush, Commerce and its Discontents in Eighteenth-Century French Political Thought, Cambridge, Cambridge University Press, 2013.

Viejo, Julián, «El amor propio en el infierno. Pasiones y Gobierno en la Monarquía hispana» en Pablo Fernández Albaladejo, Fénix de España. Modernidad y Cultura propia en la España del siglo XVIII, Madrid, Marcial Pons, 2006: 73-92.

Viejo, Julián, Amor propio y sociedad comercial en el siglo XVIII hispano, Bilbao, UPV-EHU, 2018.

Viejo, Julián y Portillo, José M. a , «Un buen amor propio. Aceptación católica de una sociedad comercial en la Monarquía hispánica del siglo XVIII», Espacio, Tiempo, Forma, Serie IV/26 (Madrid, 2013): 127-143.

Villanueva, Joaquín Lorenzo, Catecismo del Estado, Madrid, Imprenta Real, 1793.

Voltaire [François-Marie Arout], «Extrait de la Nouvelle Bibliothèque (novembre, 1740)», en Voltaire, Oeuvres Complétes de Voltaire. Nouvelle édition, París, Garnier Frères, 1879, tomo 23, Mélanges II: 159-163.

Wennerlind, Charles y Schabas, Margaret, David Hume's Political Economy, Londres, Routledge, 2008.

Wootom, David, Power, pleasure and profit. Insatiable Appetites from Machiavelli to Madison, Cambridge, MA, Harvard University Press, 2018.

Recibido: $29 / 11 / 2019$

Aceptado: 24/11/2020 